\title{
Diagnóstico de Metástases de Carcinoma Papilífero de Tiróide Através da Dosagem de Tiroglobulina no Líquido Obtido da Lavagem da Agulha Utilizada na Punção Aspirativa
}

\begin{abstract}
RESUMO
Com a introdução da ultra-sonografia cervical (USC) no seguimento dos pacientes com carcinoma papilífero de tiróide (CPT), tornou-se freqüente o encontro de pequenos linfonodos (LNs) cervicais. Porém, apesar de a USC apresentar alta sensibilidade, o estudo citológico obtido por punção aspirativa (PAAF) e, nos últimos anos, a dosagem da tiroglobulina ( $\mathrm{Tg}$ ) no lavado da agulha da PAAF (Tg-PAAF) vêm assumindo papel importante no diagnóstico de LNs cervicais. O objetivo deste estudo é verificar a acurácia da combinação da USC, citologia e Tg-PAAF em LNs suspeitos. Estudamos 32 pacientes que apresentavam 44 LNs à USC, classificados como "inflamatórios" (19) ou "suspeitos" (25). Dos 25 LNs suspeitos, 15 apresentavam Tg-PAAF elevada (13 com citologia compatível com metástases e 2 com citologia não-diagnóstica). Esses 15 LNs (11 pacientes) foram confirmados como metástase de CP pelo exame histopatológico. Os 19 LNs "inflamatórios" e os 10/25 LNs "suspeitos" apresentaram citologia negativa e Tg-PAAF indetectável. Concluímos que a USC apresenta alta sensibilidade na detecção de linfonodos cervicais, porém citologia e dosagem de Tg-PAAF são fundamentais para o diagnóstico. A associação USC, citologia e Tg-PAAF pode ser considerada a abordagem mais sensível e específica na detecção de LNs metastáticos em pacientes com CPT.
\end{abstract} (Arq Bras Endocrinol Metab 2007;51/3:419-425)

Descritores: Câncer de tiróide; Punção aspirativa com agulha fina; Tiroglobulina; Ultra-sonografia; Metástases em linfonodos

\section{ABSTRACT}

Diagnosis of Metastases in Patients With Papillary Thyroid Cancer by the Measurement of Thyroglobulin in Fine Needle Aspirate.

The widespread use of neck ultrasonography (US) during the follow-up of patients with papillary thyroid carcinoma (PTC) has led to the discovery of small cervical lymph nodes (LN). Although US has a high sensitivity for diagnosing LN, fine needle aspiration biopsy (FNA) and measurement of thyroglobulin in fine needle aspirates (FNA-Tg) have proven to be invaluable tools. The aim of this study is to determine the sensitivity of the combined use of neck US, FNA biopsy and FNA-Tg for diagnosis of cervical lymph nodes. We have studied 32 patients with 44 LN detected by US, 19 classified as inflammatory and 25 as suspicious. 15 of those 25 suspicious LN had high FNA-Tg (13 of the 15 had positive cytology and 2 indeterminate). All of these 15 LN (11 patients) were proven to be PTC metastasis by histopathology. All 19 inflammatory $L N$ and those $10 / 25$ suspicious $L N$, had cytology negative for malignancy and undetectable FNA-Tg. We conclude that fine needle aspiration biopsy and FNA-Tg combined with neck US are essential for detecting positive cervical lymph nodes due to its high sensitivity and specificity and it should be considered the standard for investigating locally recurrent disease in patients with PTC. (Arq Bras Endocrinol Metab 2007;51/3:419-425)

Keywords: Thyroid cancer; Fine needle aspiration biopsy; Thyroglobulin; Ultrasound; Lymph nodes metastases

\section{artigo original}

\author{
Rosa paula M. Biscolla \\ ELZA S. IKEJIRI \\ maria Conceiçāo Mamone \\ Cláudia C.D. Nakabashi \\ VICTOR P. ANDRADE \\ TERESA S. KASAMATSU \\ FELIPE CRISPIM \\ Maria Izabel Chiamolera \\ Danielle M. Andreoni \\ Cleber P. Camacho \\ flávio C. HOJAIJ \\ José Gilberto H. Vieira \\ REINALDO P. FURLANETTO \\ RUI M.B. MACIEL
}

Disciplina de Endocrinologia, Departamento de Medicina, Escola Paulista de Medicina, Universidade Federal de São Paulo, e Laboratório Fleury (VPA), São Paulo, SP.

Recebido em 25/04/06

Revisado em 03/10/06

Aceito em 08/10/06 
$\mathrm{O}$ TRATAMENTO DO CARCINOMA diferenciado de tiróide (CDT) (papilífero e folicular maiores de 1,0 $\mathrm{cm}$ de diâmetro) é realizado pela remoção cirúrgica do tumor, tiroidectomia total, seguido de tratamento com radiodo (131I) (1-4). Posteriormente, o seguimento inclui palpação da região cervical, ultra-sonografia cervical (USC), pesquisa de corpo inteiro com $131 \mathrm{I}$ (PCI) e dosagens de tiroglobulina sérica $(\mathrm{sTg})$ durante terapia com Levo-tiroxina (L-T4) e pós-estímulo com TSH (recombinante ou em hipotiroidismo) (1-6). Portanto, o objetivo do seguimento do paciente com CDT é a detecção precoce e o tratamento de metástases ou de doença recorrente.

A persistência de doença em leito tiroidiano ou em linfonodos geralmente associa-se a tratamento inicial incompleto (lobectomia ou tiroidectomia subtotal), variantes histológicas mais agressivas (carcinoma papilífero esclerosante difusa, células altas e outras), impossibilidade de remoção completa de alguns tumores (seja no leito tiroidiano ou por invasão em tecidos moles) ou pela falta de remoção de linfonodos metastáticos (4,7-9). Por outro lado, recorrência é definida como evidência de doença de 6 a 12 meses após o paciente ser considerado livre de doença; das recorrências cervicais, $20 \%$ ocorrem em leito tiroidiano e $60-75 \%$ em linfonodos $(7,8,10,11)$.

Nos últimos anos, a USC assumiu papel fundamental no seguimento dos pacientes com carcinoma papilífero de tiróide e deve ser realizada de rotina em todos os pacientes, independentemente do risco inicial, sendo considerada o exame mais sensível para o diagnóstico das recorrências e metástases cervicais $(2-4,6,8,12)$.

Embora a dosagem de sTg seja considerada o método mais sensível para o diagnóstico precoce de metástases do carcinoma diferenciado de tiróide, 20\% dos pacientes com metástases em linfonodos cervicais apresentam níveis indetectáveis de sTg em uso de LT4 (13). Por outro lado, metástases linfonodais podem não captar iodo radiativo em $20-40 \%$ dos casos, mesmo quando o exame é realizado após altas doses de 131I $(14,15)$. Portanto, a realização da USC é essencial nos pacientes cujas metástases não secretam tiroglobulina, nem captam iodo radiativo.

Embora a sensibilidade da USC em detectar massas ocultas e linfonodos cervicais não-palpáveis esteja bem documentada, a capacidade de diferenciar linfonodos "benignos" (inflamatórios ou reacionais) de linfonodos “malignos” (metastáticos) é baixa $(12,16)$. Após a detecção de linfonodos "suspeitos" à USC, é necessária a realização de estudo citológico obtido através da punção aspirativa por agulha fina (PAAF)
(12,16-18). O estudo citológico obtido da PAAF de um linfonodo suspeito à USC apresenta valor fundamental, principalmente nos pacientes com $\mathrm{sTg}$ indetectáveis em vigência de $\mathrm{TSH}$ suprimido e naqueles com metástases não iodo-captantes. Porém 8\% das citologias de linfonodos suspeitos não são diagnósticas (16-20).

Nos últimos anos, a dosagem da $\mathrm{Tg}$, obtida do lavado da agulha utilizada na realização da PAAF (TgPAAF) em linfonodos suspeitos, tem sido proposta a fim de se diferenciar linfonodos "reacionais" (encontrados habitualmente à USC de rotina) de linfonodos "metastáticos". Vários estudos têm mostrado que altos níveis de Tg-PAAF indicam a presença de metástase de CDT, enquanto que níveis indetectáveis de Tg-PAAF afastam essa possibilidade (19-25).

Os objetivos deste estudo são: 1) verificar a acurácia da combinação da citologia e da dosagem da Tg-PAAF no diagnóstico de linfonodos encontrados à USC durante o seguimento de pacientes com CDT; 2) comparar os dados obtidos com os resultados da PCI e da dosagem de sTg.

\section{MÉTODOS}

Foram estudados 32 pacientes ( 28 mulheres e 4 homens) com diagnóstico prévio de carcinoma papilífero de tiróide. Todos os pacientes foram tratados com tiroidectomia total e 26/32 receberam terapia com radiodo (média $172 \pm 107$ $\mathrm{mCi}$, variação $30-450 \mathrm{mCi}$ ), sendo que apenas $1 / 26$ recebeu $30 \mathrm{mCi}$ para ablação de restos tiroidianos, enquanto que os demais receberam doses maiores do que $100 \mathrm{mCi}$. Em 17/32 pacientes, além da tiroidectomia total, realizouse esvaziamento ganglionar cervical.

Todos os pacientes que apresentavam linfonodos cervicais suspeitos à palpação e/ou à USC durante o seguimento (média 6,2 $\pm 5,1$ anos, intervalo 1-28 anos) foram submetidos à PAAF do linfonodo guiada por USC e dosagem de Tg-PAAF. De acordo com as características ultra-sonográficas, os linfonodos foram classificados em "linfonodos de aspecto habitual ou inflamatórios" ou "suspeitos de metástases": os "linfonodos de aspecto habitual" apresentavam forma alongada, com estria ou spot hiperecogênicos internos; enquanto que os linfonodos "suspeitos" apresentavam pelo menos uma das seguintes características: forma arredondada, ausência de estria ou spots hiperecogênicos, presença de calcificações e/ou septos.

Todos os pacientes estavam em uso de L-T4, porém alguns dados foram obtidos retrospectivamente: dosagem de sTg em hipotiroidismo, PCI diagnóstica ( 6 pacientes) e PCI pós-dose terapêutica com ${ }^{131} \mathrm{I}$ (26 pacientes). PCI diagnóstica foi realizada $48-72$ horas após $2-5 \mathrm{mCi}$ de $131 \mathrm{I}$, enquanto que PCI pós-dose terapêutica, após 72-96 horas. Utilizamos, neste estudo, os resultados mais recentes da dosagem de sTg em hipotiroidismo e da PCI. 
As dosagem de TSH foram realizadas com ensaio imunofluorométrico (Delphia) (26); as de sTg e da Tg-PAAF com ensaio imunofluorométrico (Delphia - com sensibilidade de $1 \mathrm{ng} / \mathrm{mL}$ ), e os anticorpos antitiroglobulina, em ensaio imunofluorométrico (27). O estudo foi aprovado pelo Comitê de Ética Médica da Universidade Federal de São Paulo e todos os pacientes aceitaram participar do estudo.

A USC foi realizada por um único operador utilizando-se o aparelho Aloka SSD $500 \mathrm{com}$ transdutor linear de 7,5 MHz. O material para citologia foi obtido através da PAAF guiada por USC. Após obtenção do material para estudo citológico, $1 \mathrm{ml}$ de soro fisiológico $(\mathrm{NaCl} 0,9 \%)$ é aspirado pela agulha e o material obtido, armazenado em freezer para posterior dosagem. Como já descrita anteriormente, a dosagem da Tg-PAAF foi realizada com ensaio imunofluorométrico - Delphia, utilizando-se o mesmo protocolo para dosagem de sTg. De acordo com os resultados da citologia e da Tg-PAAF, os linfonodos foram classificados em 2 grupos: "linfonodo reacional", quando a citologia mostrava presença de linfócitos em diferentes estágios de maturação e dosagem de Tg-PAAF indetectável; "linfonodo metastático", quando à citologia encontravam-se células foliculares em substituição à população linfocitária e/ou a dosagem de Tg-PAAF elevada. Em 6 pacientes o resultado citológico foi prejudicado pela pequena quantidade de material obtido e a citologia foi classificada como "não-diagnóstica".

\section{RESULTADOS}

\section{Achados USC}

Durante o seguimento dos 32 pacientes, 44 linfonodos foram avaliados (9 pacientes apresentavam mais de 1 linfonodo). De acordo com as características à USC, 19 linfonodos apresentavam aspecto habitual e 25 linfonodos eram "suspeitos". O diâmetro médio dos linfonodos à USC era de $1,3 \pm 0,5 \mathrm{~cm}(0,6-3,2$ $\mathrm{cm}) ; 40 \%$ dos linfonodos não eram palpáveis.

\section{Correlação entre achados USC, citologia e Tg-PAAF}

Entre os 25 linfonodos considerados "suspeitos" à USC, 13 apresentavam citologia compatível com metástases de carcinoma papilífero de tiróide e dosagem de Tg-PAAF elevada variando de 256 a $17.700 \mathrm{ng} / \mathrm{dl}$ (tabela 1 , pacientes $2-7$; 9-11), ou seja, a suspeita ultra-sonográfica foi confirmada tanto pelo resultado citológico como pelas dosagens elevadas de Tg-PAAF. Dois de 25 linfonodos apresentavam citologia nãodiagnóstica (material insuficiente para análise), porém as dosagens de Tg-PAAF foram elevadas (50 e 1.500 $\mathrm{ng} / \mathrm{dl}$ respectivamente) (tabela 1 , pacientes 1 e 8 ), confirmando o diagnóstico de linfonodos metastá- ticos. Portanto, nesses pacientes, a Tg-PAAF foi fundamental para o diagnóstico e localização de metástase de carcinoma de tiróide. Finalmente, 10/25 linfonodos "suspeitos" à USC apresentavam citologia negativa (linfonodo reacional) e dosagem de Tg-PAAF indetectável $(<1,0 \mathrm{ng} / \mathrm{dl})$ com exclusão de metástase de carcinoma papilífero de tiróide. Estes resultados representam $40 \%$ de resultados falso-positivos da USC. Os 11 pacientes com diagnóstico de metástases em linfonodos $(n=15)$ foram tratados cirurgicamente com realização de esvaziamento cervical e foi confirmado diagnóstico através de exame histopatológico. Os 10/25 linfonodos restantes, com aspecto "suspeito" à US, apresentaram à citologia hiperplasia reacional e dosagens de Tg-PAAF indetectável e foram seguidos com a realização trimestral de USC.

Em relação aos pacientes que apresentavam à USC linfonodos de aspecto habitual $(n=19)$, o estudo citológico mostrou hiperplasia reacional e as dosagens de Tg-PAAF foram indetectáveis $(<1,0 \mathrm{ng} / \mathrm{dl})$, confirmando a natureza benigna dos linfonodos.

Os resultados obtidos com o estudo citológico, dosagem de Tg-PAAF em relação aos achados à USC e a conduta no diagnóstico de linfonodos reacionais ou metastáticos são apresentados no gráfico 1 .

\section{Correlação da sTg, Tg-PAAF e diagnóstico de metástases cervicais}

Com base nos resultados da citologia e Tg-PAAF, 11 pacientes apresentavam metástases em linfonodos cervicais (2 pacientes apresentavam mais de um linfonodo acometido, pacientes 7 e 11) (tabela 1). Em relação à sTg, 6/11 apresentavam sTg indetectável em vigência de TSH suprimido (pacientes 1-6) (tabela 1) e 5/11 apresentavam $\mathrm{sTg}>1,0 \mathrm{ng} / \mathrm{dl}$ (variação $1,8-5,9 \mathrm{ng} / \mathrm{dl}$ ) (pacientes 7-11) (tabela 1 , gráfico 2). Um paciente com sTg indetectável apresentava AcATg positivos (paciente 1) (tabela 1 ).

Nos 6 pacientes com sTg indetectável em uso de L-T4, a dosagem de sTg em hipotiroidismo tornou-se $>1,2 \mathrm{ng} / \mathrm{dl}$ em todos os casos (pacientes 1-6) (tabela 1, gráfico 3).

Dos 29 pacientes com linfonodos reacionais (10 linfonodos suspeitos à USC e 19 linfonodos com aspecto habitual à USC), 26 apresentavam sTg indetectável (em vigência de L-T4 e $\mathrm{sTg}<2 \mathrm{ng} / \mathrm{dl}$ em hipotiroidismo) e esses pacientes foram seguidos com realização de USC periódica. Porém, 2 pacientes apresentavam sTg detectável em uso de L-T4 (6,2 e 21 $\mathrm{ng} / \mathrm{dl}$ respectivamente); em outro paciente, apesar de sTg < 1,0 ng/dl com L-T4, houve elevação da sTg após hipotiroidismo para 4,7 ng/dl. Para esses 3 
Tabela 1. Resultados obtidos em 11 pacientes (15 linfonodos) com metástases cervicais de carcinoma papilífero de tiróide.

\begin{tabular}{|c|c|c|c|c|c|c|c|}
\hline Pac & sTg-LT 4 ng/dl & sTg hipo & AcATg & Citologia & Tg-PAAF (ng/dl) & Dose/PCI & Diam mm / Nível \\
\hline 1 & $<1,0$ & 2,1 & Pos & ND & 50 & $100 \mathrm{mCi}-\mathrm{Neg}$ & $8 / \mathrm{III}$ \\
\hline 2 & $<1,0$ & 21,5 & $\mathrm{Neg}$ & Meta & 15.600 & $30 \mathrm{mCi}-\mathrm{NR}$ & 9 / III \\
\hline 3 & $<1,0$ & 9,8 & $\mathrm{Neg}$ & Meta & 258 & $100 \mathrm{mCi}-\mathrm{LT}$ & $12 / \mathrm{III}$ \\
\hline 4 & $<1,0$ & 2,5 & $\mathrm{Neg}$ & Meta & 4.000 & $100 \mathrm{mCi}-\mathrm{Neg}$ & $20 / I V$ \\
\hline 5 & $<1,0$ & 38 & Neg & Meta & $>1.000$ & $\begin{array}{c}250 \mathrm{mCi}-\mathrm{LT}+ \\
\text { pulmão }\end{array}$ & 9 / VI \\
\hline 6 & $<1,0$ & 1,2 & $\mathrm{Neg}$ & Meta & $>1.000$ & $250 \mathrm{mCi}-\mathrm{LT}$ & $6 / \mathrm{VI}$ \\
\hline $7 \mathrm{~A}$ & 1,8 & NR & Neg & Meta & 2.949 & $100 \mathrm{mCi}-$ Linf & $13 / \mathrm{IVE}$ \\
\hline $7 \mathrm{~B}$ & 1,8 & NR & Neg & Meta & 3.400 & $100 \mathrm{mCi}-$ Linf & $30 / I V D$ \\
\hline $7 \mathrm{C}$ & 1,8 & NR & Neg & Meta & 14.257 & $100 \mathrm{mCi}-$ Linf & $15 / I V E$ \\
\hline 8 & 3,2 & NR & Neg & ND & 1.500 & $200 \mathrm{mCi}-\operatorname{Linf}$ & $12 / I V$ \\
\hline 9 & 3,9 & NR & $\mathrm{Neg}$ & Meta & 17.700 & $5 \mathrm{mCi}-\mathrm{Neg}$ & $14 / \mathrm{VI}$ \\
\hline 10 & 5,9 & NR & Neg & Meta & 1.500 & $100 \mathrm{mCi}-\mathrm{Neg}$ & 17 / IV \\
\hline $11 \mathrm{~A}$ & 3,8 & NR & Neg & Meta & $>1.000$ & $250 \mathrm{mci}-\mathrm{LT}$ & 32 / II \\
\hline $11 \mathrm{~B}$ & 3,8 & NR & Neg & Meta & $>1.000$ & $250 \mathrm{mci}-\mathrm{LT}$ & $20 / \mathrm{III}$ \\
\hline $11 \mathrm{C}$ & 3,8 & NR & $\mathrm{Neg}$ & Meta & $>1.000$ & $250 \mathrm{mci}-\mathrm{LT}$ & $12 / I V$ \\
\hline
\end{tabular}

sTg-LT : dosagem de sTg em vigência de Levo-tiroxina, sTg hipo: dosagem de sTg em vigência de TSH > $30 \mathrm{mUl} / \mathrm{ml}$, AcATg: anticorpos antitiroglobulina, Tg-PAAF: dosagem de Tg no lavado da agulha da PAAF, PCl: pesquisa de corpo inteiro, ND: nãodiagnóstica, Meta: metástase de carcinoma de tiróide, Neg: Negativo, NR: não realizado, LT: leito tiroidiano, Linf: linfonodo, D: direita, E: esquerda.

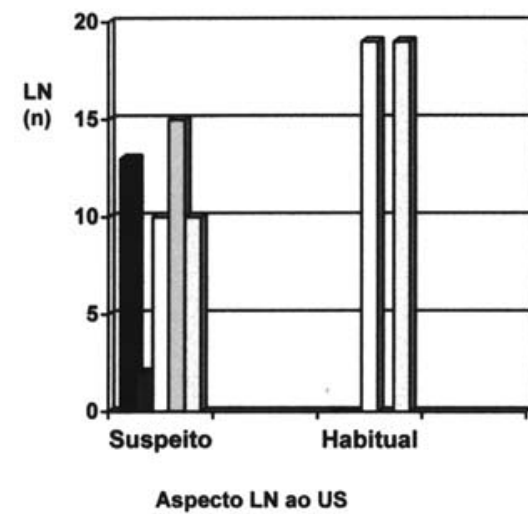

\begin{tabular}{|l|}
\hline Cito+ TgPAAF+ \\
Cito- TgPAAF+ \\
$\square$ Cito- TgPAAF- \\
$\square$ Conf Histol \\
$\square$ Seguimento USC
\end{tabular}

Gráfico 1. Comparação entre os achados US (linfonodo de aspecto habitual vs. linfonodo suspeito) com os achados citológicos, dosagem de Tg-PAAF e a conduta diagnóstica em 44 linfonodos cervicais.

Cito +: células foliculares em substituição à população linfocitária: metástases; Cito -: presença de linfócitos em diferentes estágios de maturação: linfonodo reacional; Tg-PAAF+: > $50 \mathrm{ng} / \mathrm{dl}$; Tg-PAAF -: <1,0 ng/dl; Conf Histol: confirmação histológica; USC: ultra-sonografia cervical.

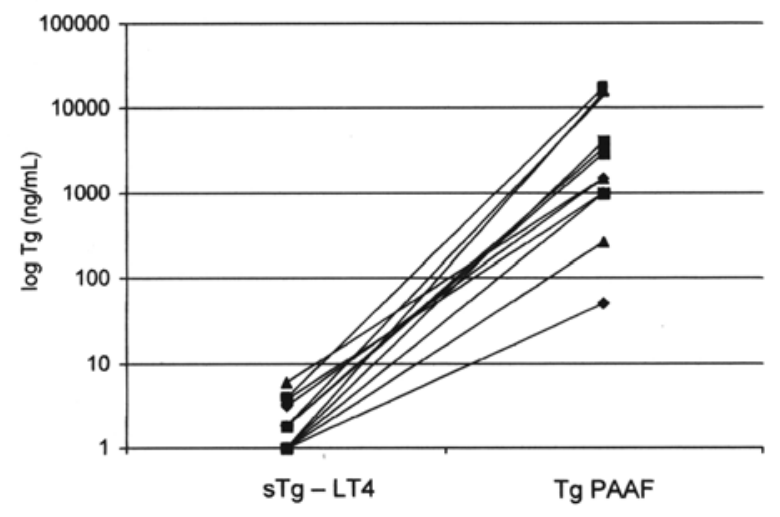

Gráfico 2. Comparação entre os níveis de sTg em vigência de L-T4 e a dosagem de Tg-PAAF em 11 pacientes com metástases em linfonodos.

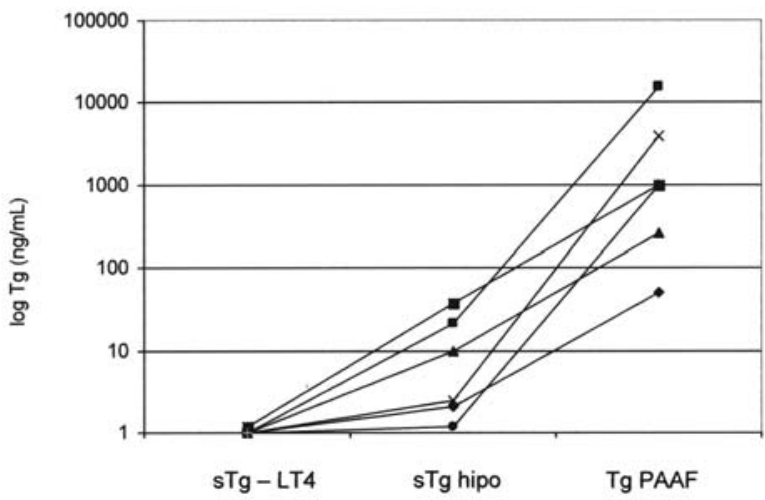

Gráfico 3. Comparação entre os níveis de sTg em vigência de L-T4, sTg em hipotiroidismo e Tg-PAAF em 6 pacientes com metástases em linfonodos. 
pacientes, optou-se por tratamento com dose terapêutica de 131I (250 mCi) com o objetivo de localização e tratamento de metástases. Em 2 pacientes o resultado da PCI não mostrou captação, assim como foram negativos os resultados de tomografia cervical e pulmonar; l paciente apresentou captação em mediastino à PCI pós-dose.

\section{Correlação entre $\mathrm{PCl}$ e metástases cervicais}

Dos 11 pacientes com metástases cervicais, 6 apresentaram captação à PCI pós-dose (100-250 mCi); 4/6 pacientes apresentaram captação em leito tiroidiano (pacientes 3,5,6,11) (tabela 1) e 2 em região cervical correspondente aos linfonodos puncionados (pacientes 7 e 8) (tabela 1). Quatro pacientes com metástases apresentaram PCI negativa: 1 paciente pós-PCI diagnóstica ( $5 \mathrm{mCi}$ ) e 3 pacientes pós-dose terapêutica com $100 \mathrm{mCi}$; $1 / 11$ paciente não realizou $\mathrm{PCI}$ pós-30 mCi de ${ }^{131} \mathrm{I}$.

\section{Dosagens de AcATg séricos e na PAAF}

Dos 32 pacientes estudados, 4 (12\%) apresentavam AcATg positivos (1 paciente com metástase cervical apresentava AcATg positivos). Neste paciente, a dosagem de sTg era indetectável em uso de L-T4 e 2,1 $\mathrm{ng} / \mathrm{dl}$ em hipotiroidismo, porém a dosagem da $\mathrm{Tg}$ PAAF foi de $50 \mathrm{ng} / \mathrm{dl}$. A dosagem dos AcATg no lavado da agulha foi negativa. Os outros 3 pacientes cujos AcATg séricos foram positivos apresentavam linfonodos inflamatórios, e as dosagens dos AcATg no lavado da agulha foram negativas.

\section{DISCUSSĀO}

Na última década, alguns grupos têm demonstrado a importância da realização de USC em pacientes com CDT que apresentam risco de recorrência da doença. $\mathrm{O}$ encontro à USC de linfonodo de forma arredondada, sem hilo central, com microcalcificações ou componente cístico e ecogenicidade similar ao tecido tiroidiano, sugere que se trate de linfonodo suspeito de metástase (12,16-18).

Atualmente, é consenso que os pacientes com AcTg negativos, submetidos a tiroidectomia total e ablação do tecido remanescente com radioiodo, com valores indetectáveis de sTg após teste de estímulo com TSH recombinante ou em hipotiroidismo, devam ser seguidos com dosagens de sTg anuais sob terapia com L-T4 e com USC (2-4).

Embora a USC apresente alta sensibilidade, é necessário realizar a PAAF para elucidação diagnóstica. Porém, $8 \%$ das citologias de linfonodos suspeitos não são diagnósticas (19-21).
A partir de 1992, alguns grupos começaram a dosar a Tg no lavado da agulha utilizada para a punção de linfonodo suspeito, a fim de discriminar se o linfonodo seria reacional ou metastático (19-25). Pacini e cols. foram os primeiros a demonstrar níveis elevados de Tg-PAAF em linfonodos com metástases de carcinoma de tiróide, enquanto que valores indetectáveis indicavam linfoadenopatia inflamatória ou de origem não-tiroidiana. Nestes pacientes, a sensibilidade da $\mathrm{Tg}$ PAAF foi de $100 \%$, enquanto que a sensibilidade da citologia foi de $85,7 \%$ (19).

Alguns anos depois, Frasodalti e cols. mostraram que a combinação da citologia com a Tg PAAF permitiu a detecção de linfonodos metastáticos em número maior que cada técnica individualmente, sendo que a realização conjunta da PAAF e da Tg-PAAF apresentava sensibilidade maior no grupo de pacientes com linfonodos cervicais do que a realização da PCI ou a dosagem de sTg (20). O mesmo grupo demonstrou recentemente, em pacientes com recorrência cervical de carcinoma diferenciado de tiróide, que a associação da dosagem de Tg-PAAF ao exame citológico aumentou a sensibilidade do método de $84,8 \%$ para $95,6 \%$ (21).

Em 2005, Mariotti e cols. demonstraram que linfonodos metastáticos apresentam níveis elevados de Tg-PAAF, enquanto que linfonodos inflamatórios apresentam níveis baixos de Tg-PAAF. Neste artigo, os autores alertam para a dosagem de Tg-PAAF em linfonodos de pacientes não-tiroidectomizados. Nesses pacientes, os autores estabeleceram um cut-off para que a dosagem de Tg-PAAF fosse discriminatória entre linfonodos reacionais ou metastáticos (25). Os demais trabalhos da literatura realizados com pacientes tiroidectomizados são concordantes em que, na ausência de tecido tiroidiano, os linfonodos reacionais apresentam níveis indetectáveis de Tg-PAAF $(19,22$, 23). Novos estudos são necessários para melhor avaliação do comportamento da Tg-PAAF em linfonodos de pacientes não-tiroidectomizados (25).

Nossos resultados confirmam o papel fundamental da USC no seguimento do paciente com CDT. Como descrito anteriormente, $40 \%$ dos pacientes apresentavam linfonodos não-palpáveis detectados à USC. Embora a USC apresente alta sensibilidade na detecção de linfonodos cervicais, a especificidade é baixa $(65 \%)$. A realização da citologia permitiu o diagnóstico de linfonodo reacional ou metastático em $95 \%$ dos pacientes com sensibilidade de $86 \%$, especificidade de $100 \%$ e valor preditivo positivo e negativo de $100 \%$. Com o acréscimo da dosagem da $\mathrm{Tg}$ PAAF, foi possível diagnosticar 2 pacientes com metástases em linfonodos, cujo resultado citológico não 
foi diagnóstico. A dosagem de Tg-PAAF nestes pacientes foi de $50 \mathrm{ng} / \mathrm{dL}$ e $1.500 \mathrm{ng} / \mathrm{dL}$, o que não deixa dúvidas sobre a natureza metastática dos linfonodos. A sTg destes pacientes em vigência de L-T4 era, respectivamente, indetectável e $3,2 \mathrm{ng} / \mathrm{dL}$, e a dosagem de AcATg era indetectável. Portanto, em 2 pacientes ( $5 \%$ dos linfonodos) a citologia não foi conclusiva, o que está de acordo com a literatura que refere resultado não-diagnóstico em $8 \%$ das citologias $(19,20)$. Concluímos então que, analisando em conjunto a citologia e a dosagem da Tg-PAAF, a sensibilidade e a especificidade passam a ser de $100 \%$.

Outro dado importante é a presença de AcATg séricos. Apenas 1 paciente com metástases apresentava AcATg positivos, com dosagem de sTg indetectável em vigência de L-T4 e 1,2 ng/dl em hipotiroidismo. Nesse paciente, a presença de AcATg provavelmente interferiu na dosagem de $\mathrm{sTg}$, mas não foi capaz de interferir na dosagem de Tg-PAAF, que era maior do que $1000 \mathrm{ng} / \mathrm{dl}$. A dosagem de AcATg no material obtido da PAAF foi negativa, ou seja, a presença de AcATg séricos parece não interferir na dosagem da Tg-PAAF.

Concluindo, a USC apresenta alta sensibilidade, porém resultados falso-positivos foram observados em $40 \%$ dos casos (linfonodos ecograficamente suspeitos com citologia negativa e TgPAAF indetectável). Com a adição da PAAF (citologia mais Tg-PAAF), a sensibilidade e a especificidade foram de $100 \%$, com valor preditivo negativo de $100 \%$ (nenhum paciente com citologia negativa e Tg-PAAF indetectável apresentou metástases cervicais durante o tempo em que foram seguidos). É importante reforçar que, em 2 pacientes, a dosagem da Tg-PAAF foi fundamental para o diagnóstico de metástases em linfonodos, sendo que 1 paciente apresentava AcATg positivos com sTg indetectável. Finalmente, a dosagem da Tg-PAAF deve ser realizada em conjunto com o estudo citológico obtido da PAAF e está indicada no seguimento de pacientes com carcinoma diferenciado de tiróide (principalmente nos carcinomas papilíferos) tratados com tiroidectomia total, cujo USC evidencia linfonodo "suspeito". Outros estudos são necessários em relação à dosagem da Tg-PAAF em pacientes nãotiroidectomizados.

\section{AGRADECIMENTOS}

Trabalho realizado com auxílio financeiro da Fundação de Amparo à Pesquisa do Estado de São Paulo (FAPESP), projeto 2004/09934-7.

\section{REFERÊNCIAS}

1. Pacini F. Follow-up of differentiated thyroid cancer. Eur $\mathbf{J}$ Med Mol Imaging 2002;29:S492-6.

2. Mazzaferri EL, Robbins RJ, Spencer CA, Braverman LE, Pacini $F$, Wartofsky L, et al. Consensus report of the role of serum thyroglobulin as a monitoring method for low-risk patients with papillary thyroid carcinoma. J Clin Endocrinol Metab 2003;88:1433-41.

3. Schlumberger M, Berg G, Cohen O, Duntas L, Jamar F, Jarzab $B$, et al. Follow-up of low-risk patients with differentiated thyroid carcinoma: an European perspective. Eur J Endocrinol 2004:150:105-12.

4. Cooper DS, Doherty GM, Haugen BR, Kloos RT, Lee SL, Mandel SJ, et al. Management guidelines for patients with thyroid nodules and differentiated thyroid cancer. Thyroid 2006;16:1-33.

5. Pacini F, Lari R, Mazzeo S, Grasso L, Taddei D, Pinchera A. Diagnostic value of a single serum thyroglobulin determination on and off thyroid suppressive therapy in the follow-up of patients with differentiated thyroid cancer. Clin Endocrinol (Oxf) 1985;23:405-11.

6. Pacini F, Molinaro E, Castagna MG, Agate L, Elisei R, Ceccarelli $\mathrm{C}$, et al. Recombinant human thyrotropin-stimulated serum thyroglobulin combined with neck ultrasonography has the highest sensitivity in monitoring differentiated thyroid carcinoma. J Clin Endocrinol Metab 2003;88:3668-73.

7. De Groot LJ, Kaplan EL, McCormick M, Strauss FH. Natural history, treatment, and course of papillary thyroid carcinoma. J Clin Endocrinol Metab 1990;71:414-24.

8. Schlumberger M, Pacini F. Papillary and follicular thyroid carcinoma. In: Thyroid Tumors. $2^{\text {nd }}$ ed. France: Nucléon, 2003. pp. 111-81.

9. Schlumberger MJ. Medical progress: papillary and follicular thyroid carcinoma. N Eng J Med 1998;338:297-306.

10. Maciel RMB, Biscolla RPM. Carcinoma papilífero e folicular da tiróide. In: Coronho V, Petroianu A, Santana EM, Pimenta LG. Tratado de Endocrinologia e Cirurgia Endócrina. $1^{\mathrm{a}}$ ed. São Paulo: Guanabara Koogan, 2001. pp. 530-42.

11. Mazzaferri EL, Kloos R. Current approaches to primary therapy for papillary and follicular thyroid cancer. $J$ Clin Endocrinol Metab 2001;86:1447-63.

12. Sutton RT, Reading CC, Charboneau JW, James EM, Grant CS, Hay ID. US-guided biopsy of neck masses in postoperative management of patients with thyroid cancer. Radiology 1988; 168:769-72.

13. Sclhumberger M, Baudin E. Serum thyroglobulin determination in the follow-up of patients with differentiated thyroid carcinoma. Eur J Endocrinol 1998;138:249-52.

14. Schlumberger M, Mancusi F, Baudin E, Pacini F. 131| therapy for elevated thyroglobulin levels. Thyroid 1997;7:273-6.

15. Maxon HR. Detection of residual and recurrent thyroid cancer by radionuclide imaging. Thyroid 1999;9:443-6.

16. Dessler A, Rapparport Y, Blank A, Marmor S, Weiss J, Graif M. Cystic appearance of cervical lymph nodes is characteristic of metastatic papillary thyroid carcinoma. J Clin Ultrasound 2003;1:21-5.

17. Rodriguez JM, Reus M, Moreno A, Martinez M, Soria T, Carrasco $L$, et al. High-resolution ultrasound associated with aspiration biopsy in the follow-up of patients with differentiated thyroid cancer. Otolaryngol Head Neck Surg 1997;117:694-7.

18. Krishnamurthy S, Bedi DG, Caraway NP. Ultrasound-guided fine-needle aspiration biopsy of the thyroid bed. Cancer 2001;93:199-204.

19. Pacini F, Fugazzola L, Lippi F, Ceccarelli C, Centoni R, Miccoli $P$, et al. Detection of thyroglobulin in fine needle aspirates of nonthyroidal neck masses: a clue to the diagnosis of metastatic differentiated thyroid cancer. J Clin Endocrinol Metab 1992;74:1401-4.

20. Frasoldati A, Toschi E, Zini M, Flora M, Caroggio A, Dotti C, et al. Role of thyroglobulin measurement in fine-needle aspiration biopsies of cervical lymph nodes in patients with differentiated thyroid cancer. Thyroid 1999;9:105-11. 
21. Frasoldati A, Pesenti M, Gallo M, Caroggio A, Salvo D, Valcavi $R$. Diagnosis of neck recurrences in patients with differentiated thyroid carcinoma. Cancer 2003;97:90-6.

22. Cignarelli M, Ambrosi A, Marino A, Lamacchia O, Campo M, Picca $G$, et al. Diagnostic utility of thyroglobulin detection in fine-needle aspiration of cervical cystic metastatic lymph nodes from papillary thyroid cancer with negative cytology. Thyroid 2003;12:1163-7.

23. Baskin HJ. Detection of recurrent papillary thyroid carcinoma by thyroglobulin assessment in the needle washout after fine-needle aspiration of suspicious lymph nodes. Thyroid 2004; 14:959-63.

24. Uruno T, Miyauchi A, Shimizu K, Tomoda C, Takamura Y, Ito $Y$, et al. Usefulness of thyroglobulin measurement in fineneedle aspiration biopsy specimens for diagnosing cervical lymph node metastasis in patients with papillary thyroid cancer. World J Surg 2005;29:483-5.

25. Boi F, Baghino G, Atzeni F, Lai ML, Faa G, Mariotti S. The diagnostic value for differentiated thyroid carcinoma metastases of thyroglobulin $(\mathrm{Tg})$ measurement in wash-out fluid from fine needle aspiration biopsy of neck lymph nodes is maintained in the presence of circulating anti-Tg antibodies. J Clin Endocrinol Metab 2006;91:1364-9.
26. Vieira JGH, Kunii IS, Nishida SK, Matsumura LK, Russo EMK, Maciel RMB. Development of an immunofluorimetric assay for the measurement of human thyrotropin (TSH) in serum and in total blood collected in filter paper. Arq Bras Endocrinol Metab 1992;36:7-12.

27. Vieira JGH, Tachibana TT, Fonseca RMG, Nishida SK, Maciel RMB. Development of an immunofluorimetric assay for the measurement of anti-thyroglobulin antibodies. Arq Bras Endocrinol Metab 1996;40:232-7.

Endereço para correspondência:

Rosa Paula M. Biscolla

Disciplina de Endocrinologia

Escola Paulista de Medicina / Universidade Federal de São

Paulo

Rua Pedro de Toledo 781, 12० andar

04039-032 São Paulo, SP

Fax: (1 1) 5084-5231

E-mail: rosapaula@uol.com.br 